Article

\title{
Measurement of Urban Park Accessibility from the Quasi-Public Goods Perspective
}

\author{
Quxiao Chen ${ }^{1, *}$, Chen Wang ${ }^{1}$, Ge Lou ${ }^{1}$, Mingyu Zhang ${ }^{1, *}$ and Shuang $\mathrm{Wu}^{2}$ \\ 1 Department of Regional and Urban Planning, College of Civil Engineering and Architecture, \\ Zhejiang University, Hangzhou 310058, China \\ 2 4A3 Design Institute, Beijing Institute of Architectural Design, Beijing 100045, China \\ * Correspondence: zhangmy18@zju.edu.cn (M.Z.); chen_qiuxiao@zju.edu.cn (Q.C.)
}

Received: 3 August 2019; Accepted: 19 August 2019; Published: 22 August 2019

\begin{abstract}
The rational distribution of parks within an urban park system should ensure reasonable travel distance for citizens, as well as good recreation quality, which seems to be more important than the former in megacities with high population density. However, studies on the accessibility of parks ignored the competitiveness and exclusiveness of urban green space, and the method can be improved to get a more scientific result as the basis for spatial optimization of urban park systems. Therefore, in this study, we consider the park's quasi-public goods attribute when building an accessibility measurement method, and both the park's service supply capacity and demand of citizens were included, as well as the influence of spatial travel cost. This method, based on the empirical research results obtained from a case study of Shaoxing in East China, provides a more suitable accessibility estimate compared with the previous methods, which can reflect the park's spatial distribution characteristics. Recommendations for improving the accessibility of parks include increasing the number of parks, reducing the cost of travel, enhancing park service capacity, and reducing the population density within the park's service area.
\end{abstract}

Keywords: urban parks; quasi-public goods; competitiveness; exclusiveness; accessibility

\section{Introduction}

Public parks represent the green land within a city that is open to the public, and their main functions include recreation, protecting the ecological environment, beautifying the landscape, and preventing disasters such as floods [1]. In China, there are four types of park according to the Classification Standard of Urban Green Space: comprehensive, community, theme, and amusement parks [2]. Studies showed that parks can promote the physical and mental health of citizens [3,4], social interaction among citizens, community awareness [5], patient recovery [6], and the construction of a sustainable and harmonious society [7]. For parks to play an active role, they must firstly be accessible; if someone wants to enjoy the services of the park, citizens must be capable of visiting one within a reasonable distance [8]. This is why park accessibility research is valuable [9].

Accessibility is the quantitative expression of the desire and ability of residents to reach a service facility or activity venue [10], and it is often reflected in transportation and land-use planning goals [11]. Park accessibility can be used to indicate its service level based on spatial distribution [12], which is considered an important factor affecting its normal functioning, subsequently influencing its use efficiency [13].

Common methods for measuring the accessibility of urban parks include the minimum distance, travel distance (including simple buffer, cost-weighted distance, and network analysis methods), and the gravity model methods. Researchers generally measured the spatial accessibility of parks from the convenience or distance of citizens to the park [14]. To measure the accessibility of parks 
in Shanghai, Yin et al. used the minimum distance method, which was the straight-line distance of residents to the nearest park [15]. Coombes et al. also used the minimum distance to express the green space accessibility in the city of Bristol, United Kingdom (UK) [16]. Nicholas adopted the simple buffer method to measure the accessibility of a park in Bryan, Texas, United States of America (USA) [12], which was able to distinguish between the accessible and inaccessible ranges of parks, but could not reflect the differences in accessibility within the accessible area. Wang found that park accessibility was overestimated when using buffer zone analysis for accessibility measurement in Changzhou [17]. Zhu et al. used the cost-weighted distance method to calculate the accessibility of forests within two kilometers of the city block [18]. Although this method's measurement results are more accurate than those of the simple buffer method, there is no unified standard for the travel resistance setting. Sang et al. used the network analysis method to calculate the accessibility of urban leisure green spaces in Hangzhou [19]. However, this method has some drawbacks; the difficulty in obtaining complete road network data and the impact on accessibility caused by the variation in park attractions due to their varying characteristics cannot be considered. The gravity model method assumes that the accessibility of the park decreases with increasing resistance experienced by citizens, and increases with the increasing service capacity of parks. This analysis method not only considers the influence of distance, but also considers the attraction effect of a park's characteristics such as size, quality, and grade [18]. Hu et al. [20] used this method to measure the accessibility of green space in Shenyang, and Ma et al. [21] used the same method in Guangzhou. Many scholars studied the exogenous factors influencing the accessibility of parks. Li et al. added influence factors of different modes of transport into accessibility evaluation [22], Xu et al. explored how the accessibility varies along socioeconomic gradients [23], and Li et al. explored the degree of matching between the accessibility of parks and residents' access preferences [24].

The above studies proposed various methods to measure the accessibility of parks, and they all simply assumed that the service capacity of each park is unlimited. However, as high-density development is a common feature of urban land use in China, park service shortages are a common problem in many cities. Restricted by factors such as the park size and its supply of facilities, citizens are competitive when enjoying park services. As the number of visitors to parks increases, the parks become crowded and overused. The higher the number of potential users of a park is, the busier and the less accessible the park is. When the spatial distribution of parks matches the population in need, the accessibility is reasonable [25]. In previous studies, the accessibility evaluations lacked consideration of users' competition in sharing the limited supply of parks.

To stabilize their normal function, some parks introduced an exclusive mechanism: charging an entrance fee. Thus, some citizens with low incomes or who are unwilling to pay the fee are excluded from enjoying the park's services. Therefore, these parks should be excluded before the evaluation of accessibility, but this was ignored in previous studies.

Paul Samuelson, the Nobel Prize laureate in Economic Sciences, stated that non-competitiveness and non-exclusivity are unique properties of public goods, differentiating them from private goods [26]. Non-competitive means that when one consumes goods, other people's consumption of the goods is not reduced. In other words, the marginal cost of increased consumers is zero. Non-exclusivity means that, whether an item is consumed by someone or not, one cannot exclude others from consuming it (whether they pay for it or not), or the cost of exclusion is very high. Objects with only one characteristic (either non-competitive or non-exclusive) are considered quasi-public goods, whereas objects without the two characteristics are considered private goods.

Due to the competitive and non-exclusive nature of public parks and the exclusive and non-competitive nature of fee-paying parks, parks should be regarded as quasi-public goods (hereinafter, QPG represents quasi-public goods) rather than pure public goods (hereinafter, PPG represents pure public goods). However, previous researchers only studied parks from the perspective of PPG; thus, from the QPG perspective, we attempted to measure the accessibility of parks using a new method to help planners identify spatial units with low park accessibility, to determine the regions that should 
be prioritized for providing park services, to lay a foundation for optimizing the layout, and to help decision-makers to develop equal and effective planning policies and strategies.

\section{Materials and Methods}

\subsection{Study Area and Data}

\subsubsection{Study Area}

The research area was in Shaoxing, a northern city in Zhejiang province in East China. Shaoxing city consists of three administrative districts, including one central urban district (Yuecheng) and two suburb districts (Shangyu and Keqiao). Meanwhile, the urban area is mainly concentrated in the Yuecheng district and had a population over seven hundred thousand at the end of 2017. Thus, in this article, Shaoxing refers to the urban area in Yuecheng district, and it is also the traditional administrative and economic center of Shaoxing city. Furthermore, Shaoxing is one of the first 24 famous historic cultural cities of China, as announced by the Chinese central government. In recognition of its contributions to improving the habitat and urban environment, Shaoxing was rated as the national garden city in 2003, and awarded the United Nations Habitat Award in 2008. Due to the efforts of the Shaoxing Municipal government, Shaoxing is much greener than other similar-sized cities. Therefore, Shaoxing was selected as the study area. The specific research scope (Figure 1) was enclosed by Erhuan Road, covering an area of $45.36 \mathrm{~km}^{2}$, which includes the old city and its surrounding areas.

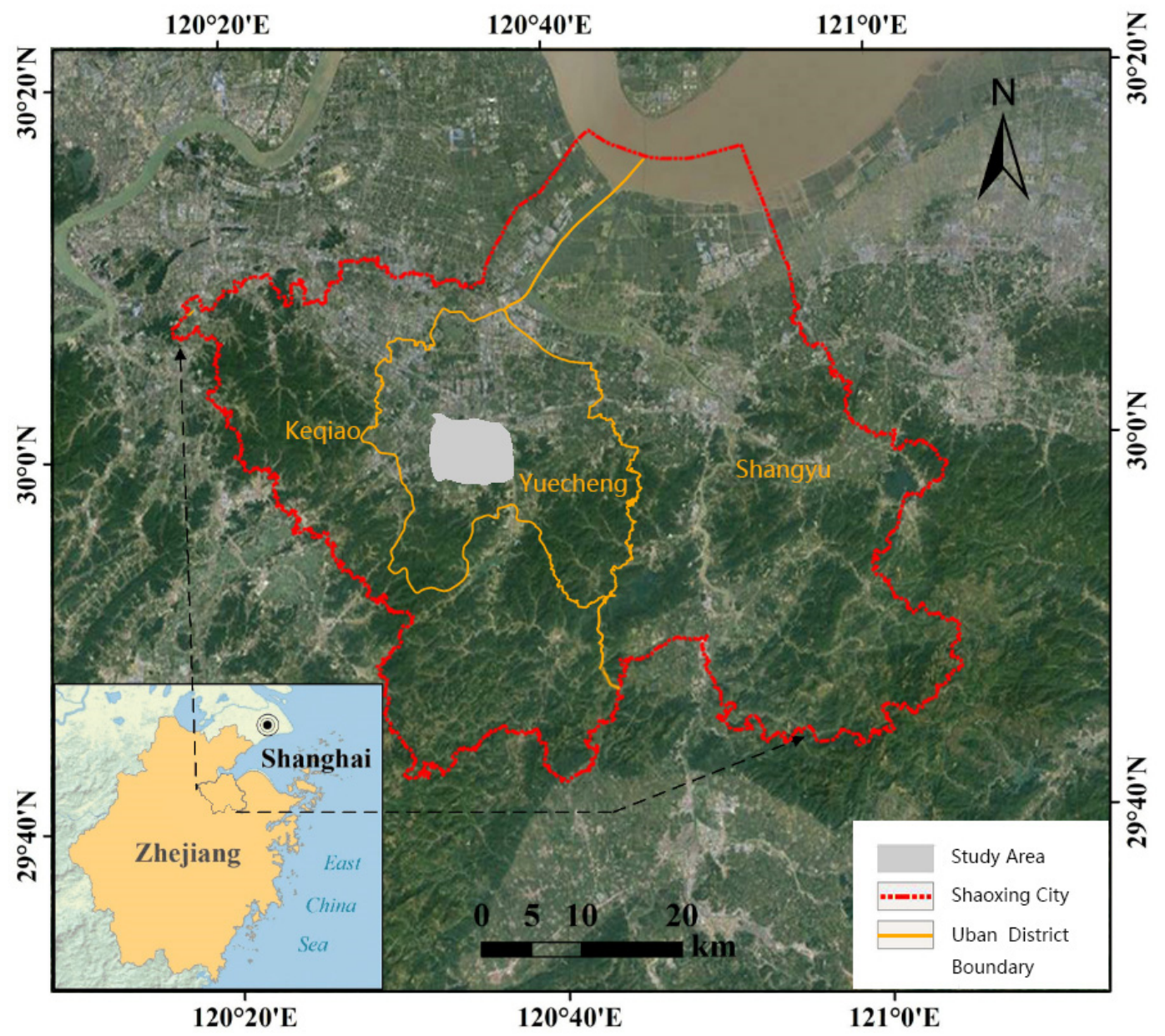

Figure 1. Location of the study area. The inset map shows the location of Shaoxing in Zhejiang province. 


\subsubsection{Data}

\section{Park Data}

In addition to the parks which need tickets, there were 41 parks in the study area (Figure 2) in 2012, including one comprehensive park, two regional parks, four community parks, three theme parks, and 16 amusement parks (consisting of 31 small independent green areas or pocket parks).

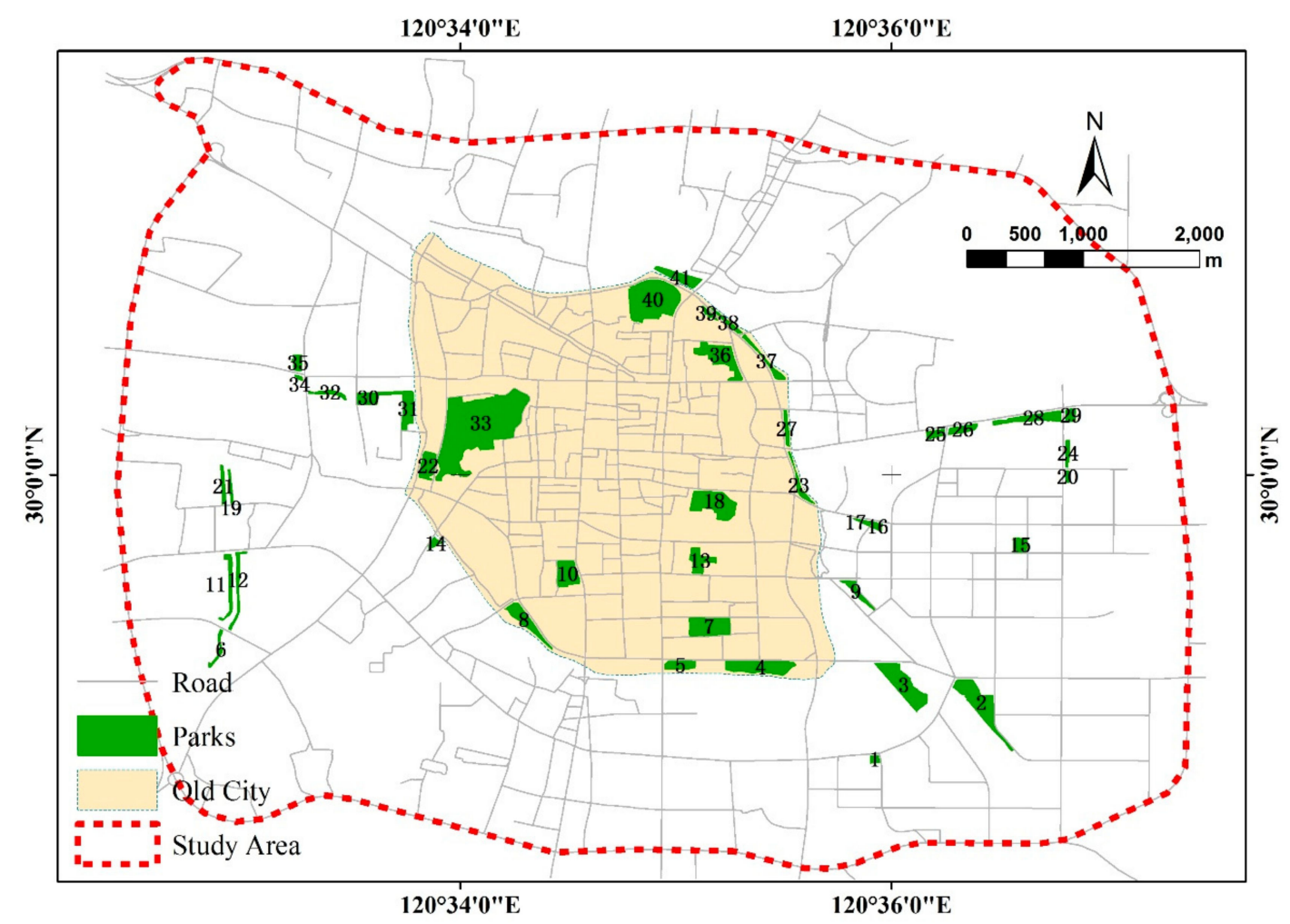

Figure 2. Spatial distribution map of parks in the study area. Data source: Shaoxing City master plan (2011-2020) and Shaoxing City green space system plan (2012-2020).

In the uncompetitive state, there are three parks (Jishan, Fushan, and Tashan) with exclusive areas where the individuals are not allowed without paying an entrance fee; thus, these areas were excluded from the method.

\section{Spatial Distribution of Population}

According to a previous study, the larger the spatial scale of the demographic unit is, the larger the estimated error of individual travel cost and the lower the accessibility accuracy will be [27]. To improve the estimation accuracy, a feasible solution involves using population data with low aggregation [28]. Therefore, taking residential buildings as basic space units, the population of these units was estimated using the following formula:

$$
\operatorname{Pop}_{i}=\operatorname{Pop}_{a v g} \times \frac{S_{i}}{S_{a v g}},
$$

where $i$ is the serial number of residential buildings, Pop $i$ denotes the population inside building $i$, Popavg is the population per household, $S_{i}$ is the area of residential buildings, and $S_{\text {avg }}$ is the story area of residential buildings per household. There are two types of residential buildings: apartment buildings and low-rise traditional buildings. $S_{a v g}$ is $116.42 \mathrm{~m}^{2}$ for the former and $60.22 \mathrm{~m}^{2}$ for the latter according to Chen et al.'s field investigation [7]. 
Based on residential building data from a 1:500 topographic map provided by Shaoxing Urban Planning Design Institute (Shaoxing, China), the story area of each building was firstly calculated by multiplying the footprint area and the story number; the story area was then multiplied by Popavg, and then divided by $S_{a v g}$ to estimate the population of the building. According to the Shaoxing Population Statistics [29], Popavg was 2.72 in 2012. The estimated total population in the research area was 424,701 , which is quite close to the real population size of 408,840 according to the census data [30]. The overall estimation error of $3.73 \%$ is acceptable since it is less than $5 \%$.

\subsection{Accessibility Measurement from the Perspective of $Q P G$}

Based on the quasi-public goods characteristic of parks, the supply of service ability and citizens' demands to parks should be considered during the accessibility measurement. The ratio of supply to demand $\left(\mathrm{ratio}_{s / d}\right)$ can reflect the accessibility to a large extent. The higher the $\mathrm{ratio}_{s / d}$ is, the more accessible the parks are. The level of accessibility is also related to the spatial resistance between travel source and destination. Considering the above two aspects, the accessibility $A_{j}$ of a specific space unit $j$ to parks can be measured according to

$$
A_{j}=\sum_{i=1}^{n} \frac{S v c_{i}}{d_{i j}^{\beta}},
$$

where $i$ is the serial number of the park, $n$ is the total number of parks, $S v c_{i}$ is the service capacity of park $i, d_{i j}$ is the space resistance from building $j$ (hereinafter referred to as the space unit) to park $i$, and $\beta$ is the gravitational attenuation coefficient.

\subsubsection{Park's Service Capacity}

Considering the quasi-public goods characteristics of parks, their service capacity is determined by the corresponding service supply and demand levels. The following measure was adopted:

$$
S v c_{i}=\frac{S_{i}}{D_{i}}
$$

where $S_{i}$ is the service supply level of the park $i$, and $D_{i}$ is the demand level of the park $i$.

Supply Level $S_{i}$

The supply level of a park is represented by the total population $S$ that can be served within the service scope of parks in a non-competitive and non-exclusive state. It is determined by two factors: the visitor capacity $C$ and the turnover coefficient $e$. The formula is as follows:

$$
S_{i}=C_{i} \times e
$$

Large parks (comprehensive parks and theme parks) have a low turnover coefficient, which represents the tourist flow speed in one day, compared with small parks due to their complete or large-scale facilities. According to relevant studies, for large parks, $e$ is $<1.5$; for small parks, $e$ is $<3$ [31]. In this study, the maximum serving population of a park in a non-competitive and non-exclusive state was used to measure the accessibility of parks. Therefore, $e$ was set to 1.5 for comprehensive parks and theme parks, and 3 for others.

\section{Park Capacity $C_{i}$}

The visitor capacity of a certain park provides the basis for management to control the number of visitors and arrange the number and scale of park facilities to avoid accidents such as visitor casualties or damage to the inside facilities caused by park overcapacity [32]. When the number of visitors is within the park capacity, the utility of a park decreases due to competition between the increasing 
visitors in the park. When the number of visitors exceeds the capacity, the park is in an unreasonably competitive state, which means that the public cannot normally enjoy the park service.

According to the relevant regulation [31], comprehensive parks own relatively complete facilities. The recreation space that visitors can use is about one-third of the total area, and the remaining two-thirds encompasses water bodies, forests, and flower beds that cannot be entered. The regulation also stipulates that the per capita occupied area of each visitor in comprehensive parks is $60 \mathrm{~m}^{2}$, whereas that of the other kinds of parks is $30 \mathrm{~m}^{2}$.

The number of visitors that a park can accommodate $\left(C_{i}\right)$ was estimated according to the following formula:

$$
C_{i}=\frac{\text { Area }_{i}}{\text { Area }_{m}}
$$

where Area $_{i}$ is the total area of park $i$ in a non-exclusive state and Area $m$ is per capital occupied area of the park for each visitor.

\section{Service Radius of Park}

The European Environment Agency recommends that people should be able to access parks within a 15-min walk [33]. Based on a Europe-wide evaluation report on the accessibility of parks, residents of several major European cities and many small cities live within the 15-min walking circle of urban parks [34]. More strictly, English Nature, a government agency, and the Swedish government recommend that people should be able to visit parks within $300 \mathrm{~m}$ of their homes [33,35]. The evaluation standard of urban landscape greening (GB/T 50563-2010) in China states that a 500-m service radius of parks should fully cover all residential land [36]. The national garden city evaluation standard requires the service radius of urban public parks (larger than $1000 \mathrm{~m}^{2}$ ) to be $500 \mathrm{~m}$ [37].

With reference to the worldwide planning guidelines, the relevant standard [2], and Chinese park system planning, e.g., Hangzhou urban green space system planning (2002-2020) or Harbin city ecological garden city green space system planning (2002-2020) [38], the park service radii were set according to their type and scale (Table 1 ).

Table 1. Service radii of parks.

\begin{tabular}{ccc}
\hline Type of Park & Area $\left(\mathbf{h m}^{\mathbf{2}}\right)$ & Service Radius $\mathbf{( k m )}$ \\
\hline & $\mathrm{S} \geq 25$ & 3 \\
& $20 \leq \mathrm{S}<25$ & 2.5 \\
Comprehensive park & $10 \leq \mathrm{S}<20$ & 2 \\
& $\mathrm{~S} \geq 10$ & 1.5 \\
& $5 \leq \mathrm{S}<10$ & 1.2 \\
& $2 \leq \mathrm{S}<5$ & 1 \\
\hline \multirow{5}{*}{ Community park } & $\mathrm{S} \geq 5$ & 1 \\
& $1 \leq \mathrm{S}<5$ & 0.8 \\
& $0.4 \leq \mathrm{S}<1$ & 0.5 \\
& $\mathrm{~S} \geq 0.4$ & 0.5 \\
\hline & $\mathrm{S} \geq 40$ & 2.5 \\
& $20 \leq \mathrm{S}<40$ & 2 \\
& $10 \leq \mathrm{S}<20$ & 1.5 \\
& $5 \leq \mathrm{S}<10$ & 1.2 \\
& $1 \leq \mathrm{S}<5$ & 1 \\
& $0.1 \leq \mathrm{S}<1$ & 0.3 \\
\hline \multirow{3}{*}{ Amusement park } & $\mathrm{S} \geq 5$ & 1 \\
& $1 \leq \mathrm{S}<5$ & 0.8 \\
& $0.1 \leq \mathrm{S}<1$ & 0.5 \\
\hline
\end{tabular}

Note: $\mathrm{S}$ represents the area of parks. 
Level of Demand for a Certain Park $D_{i}$

The demand level for a certain park is represented by the demand population within its service radius, and the formula is as follows:

$$
D_{i}=P_{i} \times \rho,
$$

where $P_{i}$ is the number of residents in the service range of park $i$, and $\rho$ is the residents' trip rate.

Due to the easy access to amusement parks, they have a relatively higher trip rate compared with other parks. According to relevant studies, the trip rate of large parks (comprehensive parks and theme parks) should be $\rho \geq 12 \%$ while that of small parks (community parks and amusement parks) should be $\rho \geq 20 \%$ [31]. In this study, the minimum demand population was considered for measuring accessibility, i.e., the trip rates of large and small parks were assigned to $12 \%$ and $20 \%$, respectively.

\subsubsection{Travel Cost and Gravity Attenuation Coefficient}

Cost of Travel $d$

Considering the spatial resistance, the network analysis method is always used to calculate the travel cost in an urban road network to evaluate park accessibility. However, the travel cost from the urban road network to residential buildings is often neglected.

As residential neighborhoods in China are always surrounded by walls, for large-scale residential areas, the travel cost inside the residential area cannot be ignored. Therefore, travel cost $d$ can be calculated as follows:

$$
d=d_{x}+d_{y}
$$

where $d_{x}$ is the distance cost within the residential quarter, and $d_{y}$ is the distance cost of the road network. Since there is always more than one entrance and exit for a residential neighborhood, as well as a park, the minimum $d$ was used for accessibility estimation.

For most citizens, the perceived park's accessibility seldom varies if the travel distance is within a certain threshold. Simultaneously, to avoid the overestimation of accessibility in the case of shorter travel distances, a 300-m travel distance threshold was set, which means that travel distances shorter than $300 \mathrm{~m}$ were regarded as $300 \mathrm{~m}$ when measuring park accessibility. If the travel distance was between $300 \mathrm{~m}$ and the service radius of the park, the real travel distance was used for measurement.

In conclusion, Equation (3) can be simplified as

$$
A_{j}=\sum_{i=1}^{n} \frac{\text { Area }_{i} \times e}{\text { Area }_{m} \times P_{i} \times \rho \times\left(d_{x}+d_{y}\right)^{\beta}} .
$$

\section{Gravity Attenuation Coefficient $\beta$}

The gravity attenuation coefficient represents the degree to which accessibility decreases with the increase in space resistance. The attraction and the accessibility of a park decrease with increasing travel distance to the park. However, no agreement was reached among scholars about a reasonable value for the gravity attenuation coefficient. Since many researchers chose 1 as the coefficient $[39,40]$, we also set $\beta$ to 1 .

\subsection{A Comparative Method from the Perspective of PPG}

To verify the difference between the proposed method from the QPG perspective and the conventional method from the PPG perspective, we used a comparison method to evaluate the accessibility. When the parks are considered as pure public goods, their service supply should fully meet the demand of individuals in their service area. Thus, Svic is 1 because the demand is equal to 
the supply. Based on the gravity method, the comparative formula from the perspective of PPG is as follows:

$$
A_{j}=\sum_{i=1}^{n} \frac{1}{d_{i j}^{\beta}} .
$$

\subsection{Data Source}

All the statistical data in this article, including the population data, were from the Shaoxing local government. Those data are all openly accessible online [29,30]. The spatial data, including the parks, road network, and buildings (both footprints and story number) were extracted from 1:500 topographic maps, which were provided by the Shaoxing Urban Planning Design Institute (Shaoxing, China).

\section{Results}

From the perspective of QPG, the actual carrying capacity of some parks cannot meet the needs of the population within the service range, and many parks have insufficient service capacity. Only seven parks, including Tashan (10; hereinafter, the number in the parentheses following the name of a park indicates its identifier (ID) in Appendix A) and Fushan (33), can fully meet the needs of all residents within the service range (Appendix A).

Thirty four parks with insufficient green space supply included amusement parks, community parks, and theme parks. Among them, the amusement parks were mainly located in the peripheral area of the old city of Shaoxing, whereas the remaining parks were mainly distributed along the boundary area near the old city.

Based on Equations (3) and (9), the accessibility values of parks within the urban area of Shaoxing, from the perspectives of PPG and QPG, were calculated, taking the residential units within the scope of the empirical research area as basic units. Assuming that parks as public goods have unlimited service supply capacity, the average accessibility of the parks of each basic unit was 2.31 , of which the highest value was 17.19. However, from the perspective of QPG, the average accessibility of parks decreased significantly, weakening to 1.27 , and the highest value was 8.52 .

To facilitate the spatial analysis and diagrams, park accessibility data from the perspective of PPG and QPG were classified and counted using the mean method, and the accessibility was divided into six categories. Among them, the basic units with 0 accessibility were regarded as a single type, and the accessibility measure values were divided into five equal ranges. From high to low, the accessibility level was classified into five categories (Table 2): level 5 (80-100\%), level 4 (60-80\%), level $3(40-60 \%)$, level $2(20-40 \%)$, and level $1(0-20 \%)$.

Table 2. Accessibility data. PPG—pure public goods; QPG—quasi-public goods.

\begin{tabular}{|c|c|c|c|c|c|c|c|c|c|}
\hline \multirow{2}{*}{ Two Perspective } & \multicolumn{5}{|c|}{ Break Points of Five Accessibility Categories } & \multirow[b]{2}{*}{ Min. } & \multirow[b]{2}{*}{ Max. } & \multirow[b]{2}{*}{ Mean } & \multirow[b]{2}{*}{ SD } \\
\hline & $\begin{array}{c}\text { Level } 1 \\
(0-20 \%)\end{array}$ & $\begin{array}{c}\text { Level } 2 \\
(20-40 \%)\end{array}$ & $\begin{array}{c}\text { Level } 3 \\
(40-60 \%)\end{array}$ & $\begin{array}{c}\text { Level } 4 \\
(60-80 \%)\end{array}$ & $\begin{array}{c}\text { Level } 5 \\
(80-100 \%)\end{array}$ & & & & \\
\hline PPG & 3.44 & 6.88 & 10.31 & 13.76 & 17.19 & 0 & 17.19 & 2.31 & 2.74 \\
\hline QPG & 1.71 & 3.41 & 5.11 & 6.82 & 8.52 & 0 & 8.52 & 1.27 & 1.51 \\
\hline
\end{tabular}

\subsection{Evaluation Results Based on Comparison Method}

Figure 3 shows the evaluation results based on the comparison method. Tables 3 and 4 show the statistical results of the number of residential units and the population, respectively. 


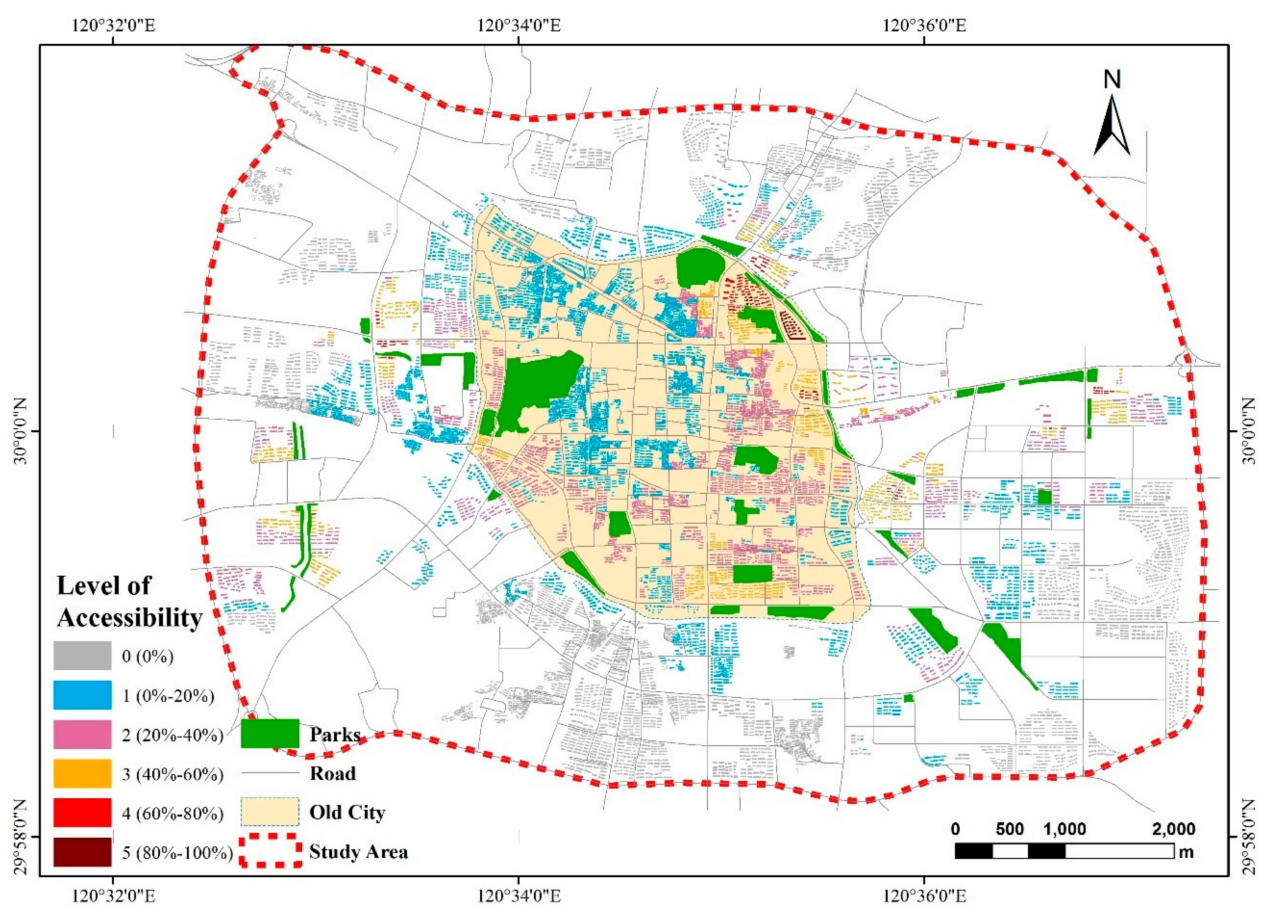

Figure 3. Accessibility evaluation results from the perspective of pure public goods (PPG). From high to low, the accessibility level was classified into five categories (Table 2).

Table 3. Statistical results of the number of units in each level from the perspective of pure public goods. The results were classified into six levels and three scopes.

\begin{tabular}{ccccccc}
\hline \multirow{2}{*}{ Accessibility Level } & \multicolumn{2}{c}{ Inside the Old City } & \multicolumn{2}{c}{ Outside the Old City } & \multicolumn{2}{c}{ Whole Study Area } \\
\cline { 2 - 6 } & Number of Units & Percentage & Number of Units & Percentage & Number of Units & Percentage \\
\hline 0 & 0 & $0.00 \%$ & 5205 & $60.02 \%$ & 5205 & $38.94 \%$ \\
1 & 2495 & $53.14 \%$ & 2085 & $24.04 \%$ & 4580 & $34.26 \%$ \\
2 & 1713 & $36.49 \%$ & 858 & $9.89 \%$ & 2571 & $19.23 \%$ \\
3 & 385 & $8.20 \%$ & 472 & $5.44 \%$ & 857 & 121 \\
4 & 69 & $1.47 \%$ & 52 & $0.60 \%$ & 33 & $0.91 \%$ \\
5 & 33 & $0.70 \%$ & 0 & $0.00 \%$ & $136 \%$ \\
Total & 4695 & $100.00 \%$ & 8672 & $100.00 \%$ & $100.00 \%$ \\
\hline
\end{tabular}

Table 4. Statistical results of the population in each level from the perspective of pure public goods. The results were classified into six levels and three scopes.

\begin{tabular}{ccccccc}
\hline \multirow{2}{*}{ Accessibility Level } & \multicolumn{2}{c}{ Inside the Old City } & \multicolumn{2}{c}{ Outside the Old City } & \multicolumn{2}{c}{ Whole Study Area } \\
\cline { 2 - 6 } & Population $(\boldsymbol{n})$ & Percentage & Population $(\boldsymbol{n})$ & Percentage & Population $(\boldsymbol{n})$ & Percentage \\
\hline 0 & 0 & $0.00 \%$ & 153,513 & $51.69 \%$ & 153,513 & $36.15 \%$ \\
1 & 61,032 & $47.78 \%$ & 75,977 & $25.58 \%$ & 137,009 & $32.26 \%$ \\
2 & 48,884 & $38.27 \%$ & 40,754 & $13.72 \%$ & 89,638 & $21.11 \%$ \\
3 & 12,959 & $10.15 \%$ & 24,122 & $8.12 \%$ & 37,081 & $8.73 \%$ \\
4 & 3416 & $2.67 \%$ & 2598 & $0.87 \%$ & 6014 & $1.42 \%$ \\
5 & 1446 & $1.13 \%$ & 0 & $0.00 \%$ & 1446 & $0.34 \%$ \\
Total & 127,737 & $100.00 \%$ & 296,964 & $100.00 \%$ & 424,701 & $100.00 \%$ \\
\hline
\end{tabular}

Even when considering the unlimited service capacity of parks, $38.94 \%$ of residential units in Shaoxing were not within the service scope of the urban park system. In particular, urban parks in the north and south of the study area were relatively few and small, preventing a large number of basic residential units in the above area to enjoy park services. Due to the growth of the urban population and the expansion demand of urban land in the Shaoxing urban area, many suburbanized residential areas, with gated communities as the main type, appeared in the market-led suburbanization development process. Simultaneously, the government-led public service facilities, including park and green space 
facilities, were relatively behind in terms of construction, which means that this type of residential area is a suburban "sleeping city" that lacks parks and green space services. Newly built residential areas in the periphery of the city tended to be spatially scattered, with many independent development plots. The parks were far from the surrounding original residential groups, with poor spatial agglomeration; thus, the existing park system in the Shaoxing urban area was unable to cover the peripheral areas.

In addition to many basic units outside the service scope of parks in suburbs, the accessibility of parks in more than half of the basic units was relatively low, among which level 1 accounted for $34.26 \%$ and level 2 accounted for $19.23 \%$ of the total. In terms of spatial distribution, the proportion of basic units with low accessibility was much higher within than outside Shaoxing old city. The total number of basic units in levels 1 and 2 accounted for nearly $90 \%$, which accommodated nearly 110,000 urban residents. The number of basic units with high accessibility, levels 4 and 5, was relatively low, accounting for only $1.16 \%$ of the total. The units with high accessibility were in the northeast of Jishan park (40) and Dongdachi park (36). The buildings along Yan'andong Road, Renmin East Road, and around Hechi park (16, 17), Dongdachi park (36), and Nanyunhe park $(6,11,12,19,21)$ also showed a relatively high park accessibility.

From the perspective of PPG, the park accessibility of basic units within the research scope reflected significant spatial heterogeneity. Even if the existing park system could provide an unlimited supply in a non-exclusive and non-competitive state, nearly $40 \%$ of the building units still would not enjoy the effective services of parks. Among the building units enjoying park services, many with low accessibility were concentrated in the urban center and suburban areas. Especially from the center to the northwest of the old city, due to the relatively few green parks, there was a large continuous distribution of poorly accessible areas. However, in the southeast side of the old city, the accessibility level of basic units was relatively high due to the number and dense spatial distribution of parks.

\subsection{Evaluation Results Based on Proposed Method}

Figure 4 shows the evaluation results based on the proposed method. Tables 5 and 6 show the statistical results of the number of units and the population, respectively.

Table 5. Statistical results of the number of units in each level from the perspective of quasi-public goods. The results were classified into six levels and three scopes.

\begin{tabular}{ccccccc}
\hline \multirow{2}{*}{ Accessibility Level } & \multicolumn{2}{c}{ Inside the Old City } & \multicolumn{2}{c}{ Outside the Old City } & \multicolumn{2}{c}{ Whole Study Area } \\
\cline { 2 - 6 } & No. Units & Percentage & No. Units & Percentage & No. Units & Percentage \\
\hline 0 & 0 & $0.00 \%$ & 5205 & $60.02 \%$ & 5205 & $38.94 \%$ \\
1 & 1874 & $39.91 \%$ & 2109 & $24.32 \%$ & 3983 & $29.80 \%$ \\
2 & 2007 & $42.75 \%$ & 740 & $24.32 \%$ & 2747 & $20.55 \%$ \\
3 & 800 & $17.04 \%$ & 372 & $4.29 \%$ & 1172 & $8.77 \%$ \\
4 & 14 & $0.30 \%$ & 168 & $1.94 \%$ & 182 & $1.36 \%$ \\
5 & 0 & $0.00 \%$ & 78 & $0.90 \%$ & 78 & $0.58 \%$ \\
Total & 4695 & $100.00 \%$ & 8672 & $100.00 \%$ & 13367 & $100.00 \%$ \\
\hline
\end{tabular}

Table 6. Statistical results of population in each level from the perspective of quasi-public goods. The results were classified into six levels and three scopes.

\begin{tabular}{ccccccc}
\hline \multirow{2}{*}{ Accessibility Level } & \multicolumn{2}{c}{ Inside the Old City } & \multicolumn{2}{c}{ Outside the Old City } & \multicolumn{2}{c}{ Whole Study Area } \\
\cline { 2 - 6 } & Population $(\boldsymbol{n})$ & Percentage & Population $(\boldsymbol{n})$ & Percentage & Population $(\boldsymbol{n})$ & Percentage \\
\hline 0 & 0 & $0.00 \%$ & 153,513 & $51.69 \%$ & 153,513 & $36.15 \%$ \\
1 & 43,578 & $34.12 \%$ & 81,320 & $27.38 \%$ & 124,898 & $29.41 \%$ \\
2 & 56,883 & $44.53 \%$ & 32,852 & $11.06 \%$ & 89,735 & $21.13 \%$ \\
3 & 26,526 & $20.77 \%$ & 17,852 & $6.01 \%$ & 44,378 & $10.45 \%$ \\
4 & 750 & $0.59 \%$ & 7322 & $2.47 \%$ & 8072 & $1.90 \%$ \\
5 & 0 & $0.00 \%$ & 4105 & $1.38 \%$ & 4105 & $0.97 \%$ \\
Total & 127,737 & $100.00 \%$ & 296,964 & $100.00 \%$ & 4247,01 & $100.00 \%$ \\
\hline
\end{tabular}




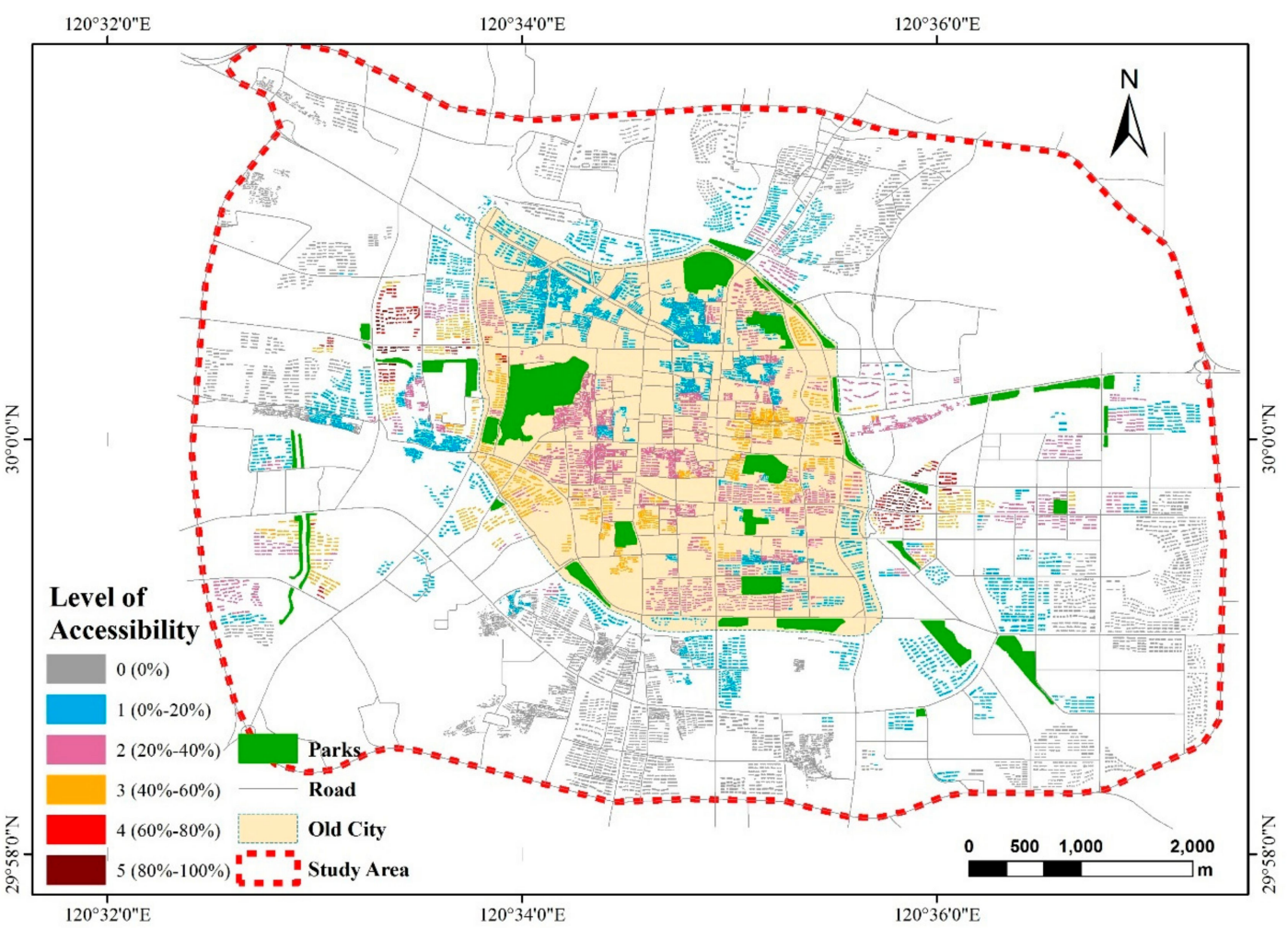

Figure 4. Accessibility result map based on the proposed method from the perspective of quasi-public goods (QPG).

When parks were considered quasi-public goods, the standard deviation of the data sample of accessibility level changed from 2.74 to 1.51 , which means that the discrete degree of the accessibility measurement value of parks decreased. The proportion of basic units for levels $2-4$ increased, reaching $20.55 \%, 8.77 \%$, and $1.36 \%$, respectively, covering about 142,000 people. The accessibility level of the basic units in the old city was mainly level 2 , reaching $42.75 \%$, mainly concentrated in the center of the old city, as well as the residential area on the east side of Fushan park (33), the southeast side of Jishan park (40), and around Luomen park (7). However, few basic units in old city had high accessibility levels (levels 4 and level 5) including the new-century apartment on the east of the old city and the Beihai community on the west side of Fushan park (33). In contrast, the basic units with high accessibility were mainly concentrated outside of the old city, including the north and south sides of Yonghe park (32), Luhu park (30), and around Hechi park $(16,17)$.

\subsection{Results Comparison}

The present spatial configuration of the park system is unequal, whether from the PPG perspective or QPG perspective. The formation of the above phenomenon was closely related to the Shaoxing space development process. Before the 1990s, Shaoxing's urbanization rate was low, and the city construction mainly centered in the old city. Since the 1990s, the old city was rated as a famous historical and cultural city in China, which means that land use and housing construction were restricted by the protection plan. Thus, urban construction started to break through the original boundary of the old city, with the eastern part chosen for public facilities and the south side chosen as a residential area for the new citizens and the old city population. After 2013, with the adjustment of the Shaoxing administrative division, the northern part gradually became the urban development hotspot. The different urban spatial expansion directions during each period and the regional function differences led to the spatial distribution differences between the inside and outside the old city, and also between the east and west parts of the study area. 
Compared with the measurement results of park accessibility from the perspective of PPG (Figure 5), more than $42 \%$ of the basic units showed different degrees of decline (Table 7 ) and spatial distribution characteristics, such as lower accessibility in the east of the study area. Among them, the most severe decreases in basic units were found around Jishan park (40), Dongdachi park (36), Luomen park (7), Nanyunhe park, and along Shunjiang Road (6, 11, 12, 19, 21). In contrast, the basic units whose accessibility decreased less were distributed along the outer areas of the city, as well as the basic units in the inner areas of the old city, such as the Huanchengxi Road area and the residential cluster around Tashan park (10). No decline was observed in the area with relatively low accessibility from the center to the southwest of the old city, mainly because the basic units in the area are near Fushan park (33), which could fully meet the needs of the population within its service area. No difference was found in the supply capacity from the perspective of PPG or QPG, guaranteeing the accessibility of the basic units.

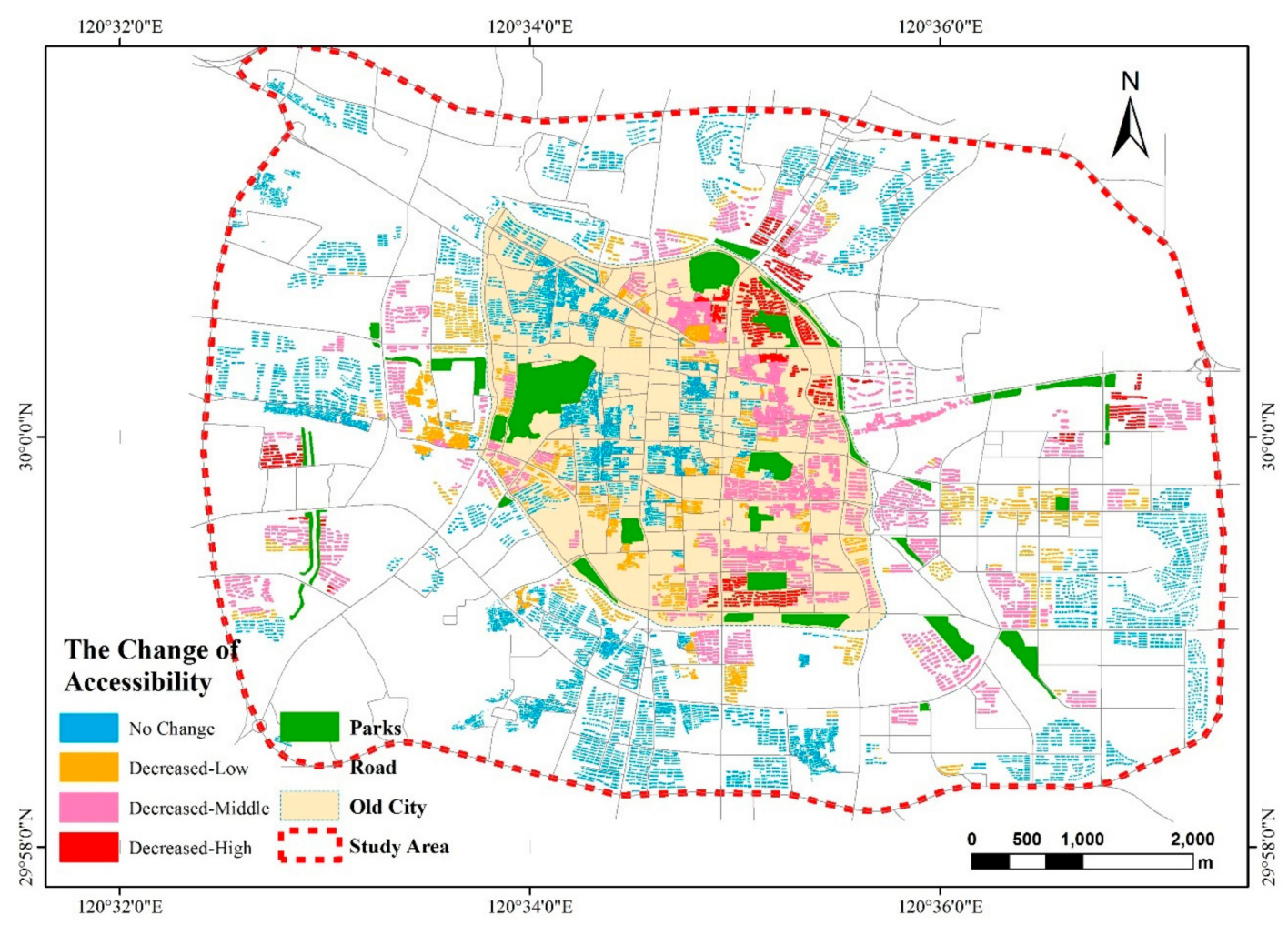

Figure 5. The change in accessibility based on the proposed and comparison methods. The park accessibility decreased or remained steady compared to that from the perspective of pure public goods.

Table 7. Statistical results of the number of units within each level from the change in accessibility based on the proposed and comparison methods. The results were classified into six levels and three scopes.

\begin{tabular}{ccccccc}
\hline \multirow{2}{*}{ Change in Accessibility } & \multicolumn{2}{c}{ Inside the Old City } & \multicolumn{2}{c}{ Outside the Old City } & \multicolumn{2}{c}{ Whole Study Area } \\
\cline { 2 - 7 } & No. Units & Percentage & No. Units & Percentage & No. Units & Percentage \\
\hline No Change & 2008 & $42.77 \%$ & 5693 & $65.65 \%$ & 7701 & $57.61 \%$ \\
Decrease & 2687 & $57.23 \%$ & 2979 & $34.35 \%$ & 5666 & $42.39 \%$ \\
Total & 4695 & $100.00 \%$ & 8672 & $100.00 \%$ & 13,367 & $100 \%$ \\
\hline
\end{tabular}

\section{Discussion}

From the perspective of QPG, the method of measuring park accessibility reflected a more suitable evaluation of the service capacity of the urban park system and the ability of residential units to obtain park services, compared with the accessibility analysis method from the perspective of PPG. The most 
significant difference was in the assessment of the real service capacity of parks. Considering the nature of quasi-public goods, taking only the spatial proximity as the influencing factor in the research about accessibility would lead to the overestimation of the accessibility and hide the problems with the park system's spatial layout, as evidenced by the Shaoxing old city. Although there are three comprehensive parks in Shaoxing old city, the increase in population in this area promoted the demand for parks, resulting in the actual park accessibility of the living space in the old city being relatively low.

Based on Equation (9), from the perspective of PPG, for a specific urban space, the factors affecting its accessibility are the number of surrounding parks and travel costs. Therefore, by optimizing the park system, increasing the number of parks could increase the spatial density of parks and reduce the citizens' travel costs, which is important to rapidly enhance the accessibility. However, considering parks as quasi-public goods in this accessibility measurement method, the factors influencing accessibility are expanded to the park scale, park turnover rate, per capita area of parks, the number of surrounding residents, and trip rate of park services. Those influencing factors can be divided into three categories: the correlation influencing factors, which mainly refer to the spatial relationship between the basic unit and surrounding parks, including the number of surrounding parks and travel costs; environmental factors, which mainly refer to the number of residents within the park service area; and type factors, which are directly related to the types of parks, including the park turnover rate, the rate of residents around the park, and the per capita occupied area of parks.

According to the proposed method, the number of surrounding parks, the turnover rate of parks, and the park area positively influenced accessibility, whereas travel cost, the number of residents within the park's service range, the travel rate of residents, and the per capita area of parks were all negatively correlated. Therefore, for the park system, the accessibility can be improved by changing the type factors, such as increasing the non-exclusive service area of parks. In addition, the service capacity of parks can be enhanced by increasing the turnover rate and reducing the per capita occupancy of the park area to improve the overall service capacity of the park system. For residential units, the spatial difference of accessibility is also affected by environmental and correlation influencing factors, such as the location and the population density of nearby residential areas.

Therefore, the accessibility level is related to the correlation factors including spatial proximity of a park to the citizens and the number of surrounding parks. Environmental factors also exert an important influence on park accessibility. However, the type factors, which include the park's own characteristics, are not determined by the nearby residential units. So, the environmental factors and correlation factors play more critical role in accessibility change. In this article, we take the change in accessibility of residential units as the dependent variable, and the park service supply capacity (measured by the number of nearby parks), spatial proximity (the average road network distance to nearby parks), nearby population density (the storey height of building units) as the independent variables.. We used the least squares method to analyze the influence of various factors on the change in accessibility. All units with zero accessibility were removed in this analysis to improve the effectiveness of regression analysis which was performed by IBM SPSS Statistics V22.0. Based on the data analysis results, the regression equation can generally describe the relationship between the dependent variable and independent variables (coefficient of determination $\left(R^{2}\right)>0.6$ ). The significance test showed that the number of surrounding parks, the average network distance, and the story condition of residential units had a significant impact on the change in accessibility level. In the regression formula, we found a significant positive correlation between the number of parks and the decline in accessibility, indicating that the more concentrated the park area is, the higher the degree of accessibility decline from the perspective of QPG will be. The number of building unit stories is also positively correlated with the decrease in accessibility level. Because Shaoxing is an ancient Chinese city with a long history, differently aged architectural forms had distinct story characteristics. Inside the old city, the traditional Chinese residential houses are mostly courtyard buildings with fewer stories, usually no more than three stories. From 1949 to the 1990s, the main type of newly built houses were four- to six-story apartment buildings. In the 21st century, due to the increase in land prices and the agglomeration of 
the population, new residential communities are dominated by high-rise apartments with more than seven stories. The patchy development and cluster layout of urban construction resulted in the spatial concentration of building units in different urban development stages, and the building height of basic units is often consistent with that of surrounding areas. Therefore, the stories of the residential unit not only indicate the land-use intensity, but also the regional development intensity of the surrounding area. Thus, the increase in the number of stories means the rapid promotion of population, which leads to an increase in the total demand for parks and a further decline in accessibility. Different from the above two influencing factors, the average network distance was negatively correlated with decreasing accessibility level; the farther the average distance from the surrounding green space is, the smaller the change range of the accessibility level of residential units will be. This kind of residential units with large network distances are always in the service area of fewer parks, and they are not affected by the combined effect of the park service capacity decrease, considering that large parts of parks in Shaoxing have a lower service capacity than expected.

Due to the spatial heterogeneity of the park accessibility in Shaoxing and the differences in their formation mechanism, the strategies for optimizing the park system in Shaoxing need to match the spatial distribution characteristics in different regions. The old city has a mature park system and has almost all the comprehensive parks and theme parks. Therefore, the accessibility of parks can be improved through the following optimization strategies: firstly, increasing the non-exclusive service area in the existing parks to improve the service capacity; secondly, moving some urban residents in old city to the suburbs through the urban renewal and the historical and cultural protection processes of the old city. As part of urban renewal, the land use should be changed to promote the living quality and enhance the vitality of the city center. Thus, it is necessary to transform some residential and commercial space into small amusement parks to increase the spatial density of parks in the old city and reduce the service demand of the original parks. For the area outside the old city, the accessibility of green space can be improved mainly by optimizing the layout and type of the parks. To meet the needs of residents and to address the lack of parks in the north and south suburban areas, comprehensive parks should be included in the further city master plan and the facilities should be built as soon as possible. Large-scale amusement parks with good location condition should be upgraded to comprehensive parks to improve their service quality and expand their service capacity, such as Nanyunhe park $(6,11$, $12,19,21)$ and the river-side park on Renmin East Road $(25,26,28,29)$. Through the adjustment of factors, such as the service scale of parks and nearby service population, the optimization plan can promote the overall accessibility level of the peripheral area of Shaoxing.

Basically, we used the proposed accessibility measurement to calculate the potential park accessibility, which is a consequence of theoretical method research. Meanwhile, with attention paid to ecological protection and human living experience in the urban master plan, the proposed method could help policy-makers to plan a rational land-use layout which has a more balanced residential, working, and leisure space. However, the proposed method has as least two drawbacks: firstly, the measurement lacks citizen investigation to understand the practical willingness to obtain park services, leading to the turnover rate potentially being overestimated or underestimated; secondly, the measurement ignores the individuality of each park. Uniform standards of trip rate and per capita occupied area were used in the measurement of the same kind of parks. The above deficiencies would somehow affect the accuracy of the estimated park accessibility. Therefore, in further research, it is necessary to have field investigations for enriching the data source and to use the multi-fractal model for improving the accuracy of the evaluation method [41]. Furthermore, based on big data such as mobile phone signals, the theoretical method also needs comparative empirical research to verify its reliability.

Author Contributions: Conceptualization, Q.C., S.W. and C.W.; methodology, Q.C., S.W. and M.Z.; software, C.W. and G.L.; formal analysis, Q.C. and C.W.; validation, C.W., G.L., and M.Z.; investigation, Q.C., M.Z., and S.W.; resources, Q.C. and S.W.; data curation, G.L. and M.Z.; writing-original draft preparation, Q.C., C.W., G.L., and M.Z.; writing-review and editing, Q.C., C.W., G.L., and M.Z.; visualization, G.L. and M.Z.; supervision, Q.C. and S.W.; project administration, Q.C. and C.W.; funding acquisition, Q.C. 
Funding: This study was financially supported by the National Key Research and Development Program of China (2018YFD1100302-04).

Conflicts of Interest: The authors declare no conflict of interest.

\section{Appendix A}

Table A1. The basic information of parks.

\begin{tabular}{|c|c|c|c|c|}
\hline No. & Name of Park & Type & Supply-Demand Ratio & Location * \\
\hline 1 & Lujiazhuang Park & Amusement park & 0.20 & Outside \\
\hline 2 & Pingshuixijiang river-side green land & Amusement park & 0.10 & Outside \\
\hline 3 & Jiangnan amusement park & Theme park & 0.33 & Outside \\
\hline 4 & Jishui park & Amusement park & 0.31 & Inside \\
\hline 5 & Jianshui park & Amusement park & 0.31 & Inside \\
\hline 6 & 3rd Nanyunhe park & Amusement park & 0.15 & Outside \\
\hline 7 & Luomen park & Community park & 0.27 & Inside \\
\hline 8 & Zhishui square & Amusement park & 0.50 & Inside \\
\hline 9 & Dongfang garden & Community park & 0.48 & Outside \\
\hline 10 & Tashan park & Regional park & 1 & Inside \\
\hline 11 & 4th Nanyunhe park & Amusement park & 0.41 & Outside \\
\hline 12 & 5th Nanyunhe park & Amusement park & 1 & Outside \\
\hline 13 & Shen park & Theme park & 0.49 & Inside \\
\hline 14 & Changxi crossing park & Amusement park & 1 & Outside \\
\hline 15 & Xiban park & Community park & 0.95 & Outside \\
\hline 16 & 1st Hechi park & Amusement park & 1 & Outside \\
\hline 17 & 2nd Hechi park & Amusement park & 0.74 & Outside \\
\hline 18 & Ertong park & Theme park & 1 & Inside \\
\hline 19 & 1st Nanyunhe park & Amusement park & 0.07 & Outside \\
\hline 20 & 1st Shunjiang Road park greenbelt & Amusement park & 0.10 & Outside \\
\hline 21 & 2nd Nanyunhe park & Amusement park & 0.14 & Outside \\
\hline 22 & Xi park & Amusement park & 0.14 & Inside \\
\hline 23 & 1st river-side green land on Huancheng East Road & Amusement park & 0.37 & Inside \\
\hline 24 & 2nd Shunjiang Road park greenbelt & Amusement park & 0.35 & Outside \\
\hline 25 & 1st river-side park on Renmin East Road & Amusement park & 0.52 & Outside \\
\hline 26 & 2nd river-side park on Renmin East Road & Amusement park & 0.38 & Outside \\
\hline 27 & 2nd river-side green land at Huancheng East Road & Amusement park & 0.49 & $\begin{array}{l}\text { Inside } \\
\text { Inside }\end{array}$ \\
\hline 28 & 3rd river-side park at Renmin East Road & Amusement park & 0.09 & Outside \\
\hline 29 & 4th river-side park at Renmin East Road & Amusement park & 0.18 & Outside \\
\hline 30 & Luhu park & Amusement park & 0.53 & Outside \\
\hline 31 & Henghe greenbelt & Amusement park & 1 & Outside \\
\hline 32 & Yonghe park & Amusement park & 0.11 & Outside \\
\hline 33 & Fushan park & Citywide park & 1 & Inside \\
\hline 34 & 1st Shenglixi Road green space & Amusement park & 0.95 & Outside \\
\hline 35 & 2nd Shenglixi Road green space & Amusement park & 0.89 & Outside \\
\hline 36 & Dongdachi park & Community park & 0.07 & Inside \\
\hline 37 & 3rd river-side green land on Huancheng East Road & Amusement park & 0.43 & Inside \\
\hline 38 & 4th river-side green land on Huancheng East Road & Amusement park & 0.20 & Inside \\
\hline 39 & 5th river-side green land on Huancheng East Road & Amusement park & 0.19 & Inside \\
\hline 40 & Jishan park & Regional park & 0.09 & Inside \\
\hline 41 & Heqing park & Amusement park & 0.36 & Outside \\
\hline
\end{tabular}

* The location column describes whether the park is inside the old city: outside: the park is located outside the old city; inside: located inside the old city.

\section{References}

1. De Wrachien, D.; Mambretti, S.; Schultz, B. Flood management and risk assessment in flood-prone areas: Measures and solutions. J. Irrig. Drain. Eng. 2011, 60, 229-240. [CrossRef]

2. The Ministry of Housing and Urban-Rural Development of the People's Republic of China. Classification Standard of Urban Green Space (CJJ/T85-2017); China Building Industry Press: Beijing, China, 2017; pp. 4-5.

3. Shanahan, D.F.; Bush, R.; Gaston, K.J.; Lin, B.B.; Dean, J.; Barber, E.; Fuller, R.A. Health Benefits from Nature Experiences Depend on Dose. Sci. Rep. 2016, 6, 28551. [CrossRef]

4. Webster, C.; Sarkar, C.; Melbourne, S.J.; Pryor, M.; Tang, D.; Kafafy, N. Green equals healthy? Towards an evidence base for high density healthy city research. Landsc. Archit. Front. 2015, 3, 8-23. 
5. Sarkar, C.; Webster, C.; Pryor, M.; Tang, D.; Melbourne, S.; Zhang, X.; Jianzheng, L. Exploring associations between urban green, street design and walking: Results from the Greater London boroughs. Landsc. Urban Plan. 2015, 143, 112-125. [CrossRef]

6. Ulrich, R. View through a window may influence recovery from surgery. Science 1984, 224, 420-421. [CrossRef] [PubMed]

7. Chen, Q.X.; Hou, Y.; Wu, S. Evaluation of green space accessibility of Shaoxing City Park from the perspective of opportunity fairness. Geogr. Sci. 2016, 3, 375-383.

8. Wang, D.; Brown, G.; Liu, Y. The physical and non-physical factors that influence perceived access to urban parks. Landsc. Urban Plan. 2015, 133, 53-66. [CrossRef]

9. Wang, D.; Brown, G.; Liu, Y.; Mateo-Babiano, I. A comparison of perceived and geographic access to predict urban park use. Cities 2015, 42, 85-96. [CrossRef]

10. Chen, Q.X.; Wan, L.; Yang, W. Evaluate the accessibility of urban park based on travel distance, in case of Leqing City. J. Zhejiang Univ. 2014, 3, 348-352.

11. Wendel, H.E.W.; Downs, J.A.; Mihelcic, J.R. Assessing Equitable Access to Urban Green Space: The Role of Engineered Water Infrastructure. Environ. Sci. Technol. 2011, 45, 6728-6734. [CrossRef]

12. Nicholls, S. Measuring the accessibility and equity of public parks: A case study using GIS. Manag. Leis. 2001, 6, 201-219. [CrossRef]

13. Li, W.; Zhang, L.Y. Analysis of accessibility and service efficiency of Harbin urban parks. Chin. Landsc. Archit. 2010, 26, 59-62.

14. Wu, S. Evaluation and Optimization of Urban Park from the Perspective of Quasi-Public Goods. Master's Thesis, Zhejiang University, Hangzhou, China, 2014.

15. Yin, H.W.; Kong, F.H.; Zong, Y.G. Evaluation of the accessibility and equity of urban green space. Acta Ecol. Sin. 2008, 7, 3375-3383.

16. Coombes, E.; Jones, A.P.; Hillsdon, M. The relationship of physical activity and overweight to objectively measured green space accessibility and use. Soc. Sci. Med. 2010, 70, 816-822. [CrossRef] [PubMed]

17. Wang, K. Study on the Accessibility of Urban Park Based on GIS. Master's Thesis, Nanjing Forestry University, Nanjing, China, 2012.

18. Zhu, Y.J.; Wang, C.; Jia, B.Q.; Su, J. GIS-based analysis of urban forest accessibility in Guangzhou City. Acta Ecol. Sin. 2011, 8, 2290-2300.

19. Sang, L.J.; Shu, Y.G.; Zhu, Y.P.; Su, F. Analysis on the accessibility of leisure green space in Hangzhou. Prog. Geogr. 2013, 6, 950-957.

20. Hu, Z.B.; He, X.Y.; Lu, Q.X.; Chen, W.; Li, Y.H.; Liu, C.F. GIS based greenbelt landscape accessibility research: A case of Shenyang. J. Shenyang Jianzhu Univ. 2005, 6, 671-675.

21. Ma, L.B.; Cao, X.S. Evaluation method of urban public green space landscape accessibility based on GIS. Acta Sci. Nat. Univ. Sunyatseni 2006, 6, 111-115.

22. Liu, Y.F.; Li, X.J. Measuring spatial disparity in accessibility with a multi-mode method based on parks classification in Wuhan, China. Appl. Geogr. 2018, 94, 251-261.

23. Xu, M.; Xin, J.; Su, S.; Weng, M.; Cai, Z. Social inequalities of park accessibility in Shenzhen, China: The role of park quality, transport modes, and hierarchical socioeconomic characteristics. J. Transp. Geogr. 2017, 62, 38-50. [CrossRef]

24. Li, S.J.; Ma, S.; Zhang, Y.M. Spatial pattern research on matching degree of green space accessibility and visiting preference in zhengzhou main urban area. Reg. Res. Dev. 2019, 38, 79-85.

25. Lee, G.; Hong, I. Measuring spatial accessibility in the context of spatial disparity between demand and supply of urban park service. Landsc. Urban Plan. 2013, 119, 85-90. [CrossRef]

26. Samuelson, P.A. The Pure Theory of Public Expenditure. Rev. Econ. Stat. 1954, 36, 387. [CrossRef]

27. Liu, C.F.; Li, X.M.; Han, D. Research on the accessibility of urban parks-methods and key issues. Acta Ecol. Sin. 2010, 19, 5381-5390.

28. Hewko, J.; Smoyer-Tomic, T.; Hodgson, M. Measuring neighborhood spatial accessibility to urban amenities: Does aggregation error matter? Environ. Plan. A 2002, 34, 1185-1206. [CrossRef]

29. Shaoxing People's Government. Data of Population Division of Shaoxing City. Available online: http: //www.sx.gov.cn/col/col20/index.html (accessed on 30 July 2019).

30. Shaoxing Yuecheng People's Government. Statistical Yearbook of Shaoxing Yuecheng in 2013. Available online: http://www.sxyc.gov.cn/col/col8801/index.html (accessed on 30 July 2019). 
31. Ministry of Housing and Urban-Rural Development of the People's Republic of China. Code for the Design of Public Park (GB511-92); China Building Industry Press: Beijing, China, 2016; pp. 4-5.

32. Li, Z.S. Urban Green Space Planning and Design; China Building Industry Press: Beijing, China, 2006.

33. Olga, B.; Jamie, A.; Paul, R.; Richard, G.; Richard, A.; Pat, J.; Kevin, J. Who benefits from access to green space? A case study from Sheffield, UK. Landsc. Urban Plan. 2007, 83, 187-195.

34. Stanners, D.; Bourdeau, P. Europe's Environment: The Dobříš Assessment; European Environment Agency: Copenhagen, Denmark, 1995; pp. 261-296.

35. Wray, S.; Hay, J.; Walker, H.; Staff, R. Audit of the Towns, Cities and Development Workstream of the England Biodiversity Strategy; English Nature Research Report Number 652; Natural England: York, UK, 2005.

36. Ministry of Housing and Urban-Rural Development of the People's Republic of China. Evaluation Standard of Urban Landscaping; GB/T 50563-2010; National Standards of the People's Republic of China: Beijing, China, 2010.

37. The Ministry of Housing and Urban-Rural Development of the People's Republic of China. Available online: http://www.mohurd.gov.cn/wjfb/200611/t20061101_157127.html (accessed on 30 July 2019).

38. Harbin Urban and Rural Planning Bureau. Urban Green Space System Planning of Harbin. Available online: http://www.upp.cn/view/zxgh/article/304537.html (accessed on 30 July 2019).

39. Zhou, T.G.; Guo, D.Z. GIS-based researches on urban green space on landscape gravity field with Ningbo city as an example. Acta Ecol. Sin. 2004, 2, 1157-1163.

40. Ma, L.B.; Cao, X.S. A GIS-based evaluation method for accessibility of urban public green landscape. Acta Sci. Nat. Univ. Sunyatseni 2006, 45, 111-115.

41. Frankhauser, P.; Tannier, C.; Vuidel, G.; Houot, H. An integrated multifractal modelling to urban and regional planning. Comput. Environ. Urban Syst. 2018, 67, 132-146. [CrossRef]

(C) 2019 by the authors. Licensee MDPI, Basel, Switzerland. This article is an open access article distributed under the terms and conditions of the Creative Commons Attribution (CC BY) license (http://creativecommons.org/licenses/by/4.0/). 